\title{
ARTIGO CIENTÍFICO \\ Umedecimento do substrato na germinação e vigor de sementes de Albizia niopoides Benth.
}

\author{
Substrate moisture in the germination and vigor of Albizia niopoides Benth. seeds \\ Dandara Yasmim Bonfim de Oliveira Silva ${ }^{1}$, Séfora Gil Gomes de Farias ${ }^{2}$, Caio Varonill de Almada Oliveira ${ }^{3}$, Moema \\ Barbosa de Sousa ${ }^{4}$, Romário Bezerra e Silva
}

\begin{abstract}
Resumo: A Albizia niopoides conhecida popularmente como angico branco é uma espécie florestal nativa de rápido crescimento, com elevado potencial para fins de reflorestamento. No entanto, existe pouca informação acerca de sua propagação seminífera. Dessa forma, objetivou-se avaliar o desempenho germinativo e vigor de sementes de A. niopoides sob diferentes volumes de água para umedecimento do substrato. $\mathrm{O}$ delineamento experimental utilizado foi o inteiramente casualizado, com quatro repetições de 25 sementes cada. As sementes foram semeadas em papel germitest (organizado em rolos) umedecido com volumes de água equivalentes a 1,$0 ; 1,5 ; 2,0 ; 2,5 ; 3,0 ; 3,5$ e 4,0 vezes o peso seco do substrato, sem adição posterior de água. A germinação ocorreu em câmara de germinação tipo B.O.D, regulada a temperatura de $25^{\circ} \mathrm{C}$ e sob luz contínua. As variáveis analisadas foram: porcentagem de germinação, comprimento da parte área e raiz primária, massa seca da parte aérea e sistema radicular de plântulas. Constatou-se efeito decrescente nos valores de porcentagem de germinação, comprimento da raiz primária e massa seca do sistema radicular, a partir do umedecimento do substrato com o volume de água equivalente a 2,0 vezes o seu peso seco. Os volumes de água na faixa de 1,0 a 2,0 vezes a massa do papel, favorecem a germinação e o vigor das sementes de A. niopoides.
\end{abstract}

Palavras-chave: Espécie florestal nativa; Angico branco; Volume de água; Sementes florestais.

Abstract: The Albizia niopoides, popularly known as white mimosa, is a native forest species of fast-growing and with high potential for reforestation purposes. However, there is little information about its seminiferous spread. Thus, this study aimed to evaluate the germination performance and vigor of A. niopoides seed under different water volumes for substrate moistening. The experimental design was completely randomized with four replicates and each replicate with 25 seeds. The seeds were sown on germitest paper (arranged in rolls) moistened with water volumes equivalent to $1.0 ; 1.5 ; 2.0 ; 2.5 ; 3.0 ; 3.5$; and 4.0 times the dry weight (DW) of the substrate without further water addition. Germination occurred in a germination chamber (Biochemical Oxygen Demand-B.O.D-type) set at $25{ }^{\circ} \mathrm{C}$ and continuous light. The analyzed variables were percentage of germination, length of shoot and primary root, dry weight of shoot, and root seedling system. Decreasing effect on germination percentage values, primary root length, and dry weight of the root system from the substrate moistening with the water volume equivalent to 2.0 times its dry weight were found. Water volumes in the range of 1.0 to 2.0 times the mass of paper favor the germination and vigor of A. niopoides seed.

Key words: Native forest species; White mimosa; Water volume; Forest seeds.

\footnotetext{
*Autor para correspondência

Recebido para publicação em 16/10/2016; aprovado em 27/06/2017

${ }^{1}$ Graduanda em Engenharia Florestal, Universidade Federal do Piauí, Bom Jesus; (089) 99156915, dandara.yasmim@ @otmail.com.

${ }^{2}$ Doutora, professora do Curso de Engenharia Florestal, Universidade Federal do Piauí, seflora@ gmail.com

${ }^{3}$ Mestrando em Ciência Florestal, Universidade Federal de Viçosa, caiovaronill@ gmail.com

${ }^{4}$ Graduanda em Engenharia Florestal, Universidade Federal do Piauí, sousamoema321@ @mail.com

${ }^{5}$ Doutor, professor do Curso de Engenharia Florestal, Universidade Federal do Piauí, romariobs@ gmail.com
} 


\section{INTRODUÇÃO}

A germinação sob o ponto de vista da tecnologia de sementes pode ser caracterizada como a emergência ou estabelecimento da plântula (BEWLEY et al., 2013), sendo esta influenciada por diversos fatores como: fatores intrínsecos às sementes, fatores ambientais e práticas de manejo durante e após a colheita (CARVALHO; NAKAGAWA, 2012; MARCOS FILHO, 2015). Desse modo, o conhecimento das condições adequadas para que a germinação ocorra é de fundamental importância, principalmente, pelas respostas diferenciadas que as espécies podem apresentar em função desses fatores.

A disponibilidade hídrica consiste em um dos fatores essenciais para desencadear o processo germinativo (VARELA et al., 2005). A entrada de água na semente (embebição) consiste na primeira etapa do processo germinativo, porém, para que haja a formação da plântula, torna-se necessário que a semente alcance níveis de hidratação adequados.

Assim, para condução de testes de germinação em laboratório, o substrato deve ser umedecido com níveis de água suficiente para garantir o início, a continuidade e a finalização do supracitado processo (MARCOS FILHO, 2015). Vale destacar, que tanto o excesso quanto a deficiência de água são prejudiciais à germinação.

A deficiência de água impossibilita a retomada do crescimento do eixo embrionário, dificultando a sequência dos processos bioquímicos, físicos e fisiológicos necessários para desencadear o processo germinativo (CARVALHO; NAKAGAWA, 2012), atuando na redução da velocidade e porcentagem de germinação das sementes, sendo que para cada espécie existe um valor de potencial hídrico, abaixo do qual a germinação não ocorre (BEWLEY et al., 2013). Por outro lado, o excesso de água no substrato pode resultar em alterações na disponibilidade de oxigênio para que o processo ocorra, podendo ocasionar atraso e paralisação do desenvolvimento ou, ainda, anormalidades nas plântulas, além de tornar o ambiente mais propício para aumentar a incidência de fungos (FIGLIOLIA, 2015; MARCOS FILHO, 2015)

Nesse contexto, a padronização do volume de água no substrato de acordo com as exigências da espécie, pode favorecer a germinação, além de evitar resultados conflitantes (GUEDES et al., 2010). Apesar da importância dessas informações a maioria dos trabalhos científicos não faz referência à quantidade de água adicionada aos diferentes substratos utilizados nos testes de germinação, o que pode resultar em conclusões equivocadas (MARTINS et al., 2009).

As Regras para Análise de Sementes (BRASIL, 2009) estabelecem a adição de um volume de água equivalente a dois até três vezes o peso do substrato, para o substrato tipo papel. Em areia é recomendado o umedecimento com até 50\% e $60 \%$ da capacidade de retenção de água do substrato, para sementes de cereais e de leguminosas, respectivamente.

Para espécies florestais ainda existem poucas informações disponíveis na literatura, a exemplo dos trabalhos de Varela et al. (2005) com Dinizia excelsa Ducke, Ramos et al. (2006b) com Ochroma pyramidale (Cav. ex Lam.) Urban, Ramos et al. (2006a) com Schizolobium amazonicum Huber ex Ducke, Martins et al. (2009) com Bactris gasipaes Kunth., Jatropha curcas L. (SILVA et al., 2008), Blepharocalyx salicifolius (HBK) Berg. (REGO et al.,
2009), Melanoxylon brauna Schott. (FLORES et al., 2013), Gallesia integrifolia (Spreng.) Harms (BARROS et al., 2005), Schinus terebinthifolius Raddi. (SILVA et al., 2001) e Bowdichia virgilioides Kunth. (ALBUQUERQUE et al., 2013). Pesquisas sobre as exigências de água em sementes de espécies agrícolas, realizados por Tanaka et al. (1991) e Novembre e Marcos Filho (1999) mostraram resultados consistentes, obtidos quando a umidade é controlada. Havendo assim, a necessidade de maior atenção por parte da comunidade científica para estudos de germinação relacionados ao nível de umidade do substrato, tendo em vista a sua importância. Tais informações, além de contribuir para avanços na tecnologia de sementes florestais, servem de subsídio para indicações de uso de espécies em ambientes com diferentes níveis de disponibilidade hídrica, e, assim, auxiliaria no planejamento de ações de recuperação de áreas degradadas (GUEDES et al., 2010).

Albizia niopoides conhecida popularmente como farinha seca ou angico branco, pertence à família Fabaceae e subfamília Mimosoideae (CARVALHO, 2009). É uma espécie pioneira de rápido crescimento, podendo atingir entre 10 e 22 metros de altura, podendo ser empregada na arborização, reflorestamentos mistos de áreas degradadas, empregadas em caixotaria de objetos leves, forro entre outros (LORENZI, 2002). Para a referida espécie estudos relacionado à ecofisiologia da germinação de sementes e condições adequadas para realização de testes de germinação ainda são limitados.

Diante da necessidade de informações sobre a espécie em estudo, objetivou-se avaliar o desempenho germinativo e vigor de sementes de A. niopoides, sob diferentes volumes de água para umedecimento do substrato.

\section{MATERIAL E MÉTODOS}

O experimento foi realizado no Laboratório de Ecofisiologia Florestal da Universidade Federal do Piauí campus Professora Cinobelina Elvas (UFPI/CPCE), em Bom Jesus-PI, utilizando-se um delineamento experimental inteiramente ao acaso, com quatro repetições de 25 sementes para cada tratamento (níveis de umedecimento do substrato).

Para obtenção das sementes de A. niopoides foram selecionadas quinze árvores matrizes, distanciadas aproximadamente $50 \mathrm{~m}$ entre si, localizadas em área de vegetação de transição cerrado-caatinga, no município de Bom Jesus - PI.

As matrizes foram selecionadas com base em características fenotípicas desejáveis, tais como, sanidade, maior altura do fuste, copa bem formada, boa produção de frutos /sementes, visando à obtenção de um material genético de melhor qualidade. No laboratório realizou-se a extração e beneficiamento manual das sementes.

Inicialmente, determinou-se o número de sementes por quilograma e o teor de umidade das sementes. A determinação do teor de água das sementes foi realizado pelo método padrão da estufa a $105^{\circ} \mathrm{C} \pm 3{ }^{\circ} \mathrm{C}$ (BRASIL, 2009). Antes da instalação do teste de germinação, as sementes foram submetidas à imersão em ácido sulfúrico durante um minuto, para superação da dormência, conforme recomendação de Carvalho (2009). Em seguida foram desinfestadas em solução de hipoclorito de sódio a $5 \%$ durante cinco minutos e posteriormente lavadas com água deionizada. 
O delineamento experimental utilizado foi $\mathrm{o}$ inteiramente ao acaso, com quatro repetições de 25 sementes para cada tratamento (níveis de umedecimento do substrato). Para o teste de germinação utilizou-se o substrato papel germitest no qual as sementes foram distribuídas sobre duas folhas, cobertas com uma terceira e organizados em forma de rolo. O substrato foi umedecido com solução de nistatina a $0,2 \%$ nos volumes $(\mathrm{mL})$ equivalentes a 1,$0 ; 1,5 ; 2,0 ; 2,5 ; 3,0$; 3,5 e 4,0 vezes o peso seco do substrato, sem adição posterior de água (Tabela 1).

Tabela 1. Volume de água utilizado para umedecimento do substrato.

\begin{tabular}{cc}
\hline *Teor de umidade & Volume $(\mathrm{mL})$ \\
\hline 1,0 & 21,0 \\
1,5 & 31,5 \\
2,0 & 42,0 \\
2,5 & 52,5 \\
3,0 & 63,0 \\
3,5 & 73,5 \\
4,0 & 84,0 \\
\hline
\end{tabular}

*Fator de multiplicação para determinação da quantidade de água para umedecimento do substrato.

Após o umedecimento do substrato este foi acondicionado em saco de plástico transparente de $0,04 \mathrm{~mm}$ de espessura, lacrado com ligas de plástico para evitar a perda de água e colocados em câmara de germinação do tipo Biochemical Oxigen Demand (B.O.D.) regulada a temperatura constante de $25^{\circ} \mathrm{C}$ e luz contínua.

As variáveis analisadas foram: percentagem de germinação, sendo considerado, a avaliação do número de sementes germinadas aos 15 dias após instalação do teste, adotando-se como critério de germinação o surgimento do hipocótilo com a consequente emergência dos cotilédones (BRASIL, 2009); comprimento da parte aérea e da raiz primária de plântulas, com o auxílio de uma régua realizou-se a mensuração e calculou-se a média de cada tratamento, sendo os resultados expressos em cm.plântula ${ }^{-1}$ (NAKAGAWA, 1999). Após esse procedimento, para determinação da massa seca da parte aérea e do sistema radicular, as plântulas foram separadas em raiz e parte aérea e foram colocados em sacos de papel kraft devidamente identificados e posteriormente levados à estufa regulada a $60^{\circ} \mathrm{C}$ durante 24 horas, decorrido esse período, foram pesadas em balança analítica com precisão de 0,001, sendo os resultados expressos em mg.plântula ${ }^{-1}$.

Os dados obtidos foram submetidos aos testes de normalidade (LILLIEFORS) e heterogeneidade das variâncias (COCHRAN), após verificação da não necessidade de transformação dos dados, estes foram submetidos à análise de variância (ANOVA) e as médias foram comparadas pelo teste de Tukey a 5\%. Foi realizada ainda, análise de regressão polinomial para verificar os efeitos linear, quadrático e cúbico das variáveis, em função dos tratamentos, sendo selecionado para expressar o comportamento de cada variável o modelo significativo de maior ordem. As análises estatísticas foram realizadas através do software Statistic 8.0 (STATSSOFT INC, 2008).

\section{RESULTADOS E DISCUSSÃO}

As sementes A. niopoides apresentaram 7,37\% de umidade e um número de 31.398 sementes por quilo. Carvalho (2009) em seu estudo com a mesma espécie obteve resultados superiores para umidade e número de sementes por quilograma, $9,9 \%$ e 36 mil a 36.600 sementes, respectivamente. Tais resultados podem estar relacionados com as variações individuais dentro da mesma espécie (fator genético), além da influência dos fatores ambientais durante o desenvolvimento das sementes, conforme relatado por Queiroz Diniz et al. 2015.

Constatou-se pela análise de variância, efeito significativo $(\mathrm{p} \leq 0,01)$ para as variáveis, porcentagem de germinação, comprimento da raiz primária e massa seca do sistema radicular. Esse resultado é um indicativo de que existe, no mínimo, um dos tratamentos testados que otimiza o processo germinativo das sementes em estudo.

Os maiores valores de porcentagem de germinação foram observados nos volumes de água 1,0, 1,5, 2,0 e 2,5 vezes o peso do papel seco, não diferindo entre si (Tabela 2), havendo decréscimo significativo a partir de 2,5 vezes o peso do papel seco (Tabela 2 e Figura 1). Este resultado demonstra que $A$. niopoides requer volumes menores de água para desencadear o processo germinativo.

Tabela 2 - Germinação (G\%), comprimento da parte aérea (CPA) (cm.plântula ${ }^{-1}$ ), comprimento de raiz primária (CR) (cm.plântula ${ }^{-1}$ ), massa seca da parte aérea (MSPA) (mg.plântula ${ }^{-1}$ ) e massa seca do sistema radicular (MSR) (mg.plântula ${ }^{-1}$ ) de sementes e plântulas de Albizia niopoides Benth. submetidas a diferentes níveis de umedecimento do substrato papel germitest.

\begin{tabular}{cccccc}
\hline$*$ Teor de umidade & G $(\%)$ & CPA $(\mathrm{cm})$ & CR $(\mathrm{cm})$ & MSPA $(\mathrm{mg})$ & MSR $(\mathrm{mg})$ \\
\hline 1,0 & $91 \mathrm{a}$ & $4,37 \mathrm{a}$ & $4,72 \mathrm{a}$ & $10,76 \mathrm{a}$ & $3,17 \mathrm{a}$ \\
1,5 & $96 \mathrm{a}$ & $3,97 \mathrm{ab}$ & $4,28 \mathrm{ab}$ & $9,14 \mathrm{a}$ & $2,72 \mathrm{ab}$ \\
2,0 & $90 \mathrm{a}$ & $3,98 \mathrm{ab}$ & $4,64 \mathrm{a}$ & $10,11 \mathrm{a}$ & $3,14 \mathrm{a}$ \\
2,5 & $77 \mathrm{a}$ & $3,70 \mathrm{bc}$ & $3,73 \mathrm{bc}$ & $10,39 \mathrm{a}$ & $2,72 \mathrm{ab}$ \\
3,0 & $40 \mathrm{~b}$ & $3,58 \mathrm{bc}$ & $3,50 \mathrm{~cd}$ & $8,27 \mathrm{a}$ & $2,39 \mathrm{bc}$ \\
3,5 & $19 \mathrm{~b}$ & $3,34 \mathrm{c}$ & $2,89 \mathrm{~d}$ & $10,60 \mathrm{a}$ & $2,06 \mathrm{c}$ \\
4,0 & $26 \mathrm{~b}$ & $3,68 \mathrm{bc}$ & $3,45 \mathrm{~cd}$ & $8,65 \mathrm{a}$ & $2,83 \mathrm{ab}$ \\
\hline $\mathrm{CV}(\%)$ & 18,05 & 6,46 & 8,34 & 17,56 & 8,88 \\
\hline
\end{tabular}

*Fator de multiplicação para determinação da quantidade de água para umedecimento do substrato. Médias seguidas pela mesma letra na coluna, não diferem entre si pelo teste de Tukey a $5 \%$ de probabilidade. 
Figura 1. Germinação (\%) de sementes de Albizia niopoides Benth. submetidas a diferentes níveis de umedecimento do substrato papel germitest. *Fator de multiplicação para determinação da quantidade de água para umedecimento do substrato.

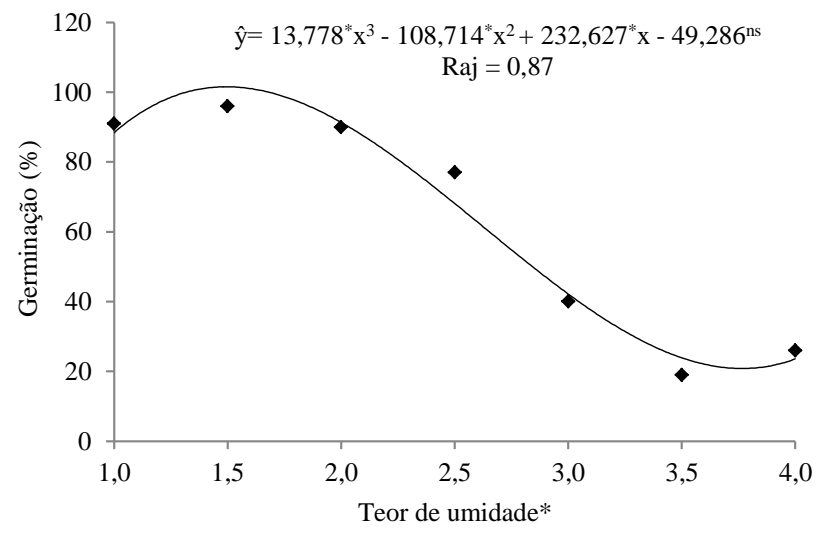

O decréscimo gradativo da germinação em função dos níveis de umedecimento do substrato pode está relacionado com o excesso de umidade no meio germinativo, o que poderia dificultar a absorção de oxigênio e restringir todo o processo metabólico resultante, podendo também aumentar a incidência de fungos, levando assim à redução no vigor de plântulas, conforme destacado por Melo et al. (2005) e Azeredo et al. (2010). Nessa perspectiva, Marcos Filho (2015) ressaltou que condições adequadas de disponibilidade hídrica, temperatura e oxigênio são fatores indispensáveis para que a germinação ocorra, e, se uma das três condições não for satisfatória a semente não germina.

Menores volumes de água também proporcionaram resultados satisfatórios nos trabalhos realizados por Ramos et al. (2006b) trabalhando com Ochroma pyramidale (Cav.) Urb., e Martins et al. (2012) nos seus estudos com Tabebuia chrysotricha (Mart. ex DC.) Standl., os quais relataram que a quantidade de 1,5 vezes a massa do substrato (papel germitest e vermiculita fina ou média, respectivamente) foi suficiente para garantir bons resultados de germinação (81, 64 e 65\%, respectivamente). Por outro lado, Ramos et al. (2006a) trabalhando com Schizolobium amazonicum Huber ex Ducke, relataram que para alcançar um melhor desempenho germinativo se faz necessário quantidades de água de 2,5 e 3,0 vezes a massa do papel germitest seco. Estudando o efeito da temperatura e volumes de água $(1,5 ; 2,0 ; 2,5$ e 3,0 mL/g de papel) na germinação de Peltogyne paniculata Benth., Ramos et al. (2007) observaram os melhores resultados quando as sementes foram acondicionadas a $25^{\circ} \mathrm{C}$ no substrato papel toalha, umedecido com 2,0 e 2,5 vezes o seu peso seco.

Outros autores reiteram a necessidade de maiores volumes de água necessários a germinação de espécies florestais, a exemplo de Nogueira et al. (2013) estudando a germinação de Mimosa caesalpiniifolia Benth. encontraram bons resultados ( $94 \%$ de germinação) quando submeteram as sementes a $25^{\circ} \mathrm{C}$, com umedecimento de 2,5 vezes o peso seco do substrato papel toalha. Barroso et al. (2014) analisando a germinação de Inga laurina (Sw.) Willd. sob diferentes temperaturas e substrato, obtiveram $86 \%$ de germinação quando as sementes foram expostas a uma temperatura de $25^{\circ} \mathrm{C}$, em substrato papel toalha com 2,5 vezes o peso do papel seco. Martins et al. (2011) estudando a influência de volumes de água nas condições de $30^{\circ} \mathrm{C}$ e substrato vermiculita, na germinação de Stryphnodendron adstringens (Mart.) Coville, obteve $71 \%$ de germinação aplicando a quantidade de água referente a 2,5 vezes o peso do papel seco.

A exigência das espécies por maior ou menor quantidade de água pode estar associada com o tamanho das sementes. De acordo com Krzyzanowski et al. (1999) sementes de menor tamanho necessitam de menores volumes de água para germinar. Nesse contexto, pode se inferir que por possuírem sementes maiores, as espécies de $S$. amazonicum e $P$. paniculata necessariamente precisam de uma maior quantidade de água para iniciar o processo germinativo quando comparadas a espécie estudada (comprimento $=5,65 \mathrm{~cm}$, largura $=4,98 \mathrm{~cm}$ e espessura $=$ 1,69 cm, dados pessoais não publicados). Carvalho e Nakagawa (2012) também mencionam que a absorção de água pela semente pode está relacionada com a composição química das mesmas, uma vez que quanto maior o conteúdo de proteínas nas sementes, mais rápido será o processo de embebição.

No que se refere à quantidade de água a ser utilizada, nota-se que as espécies apresentam exigências hídricas diferentes, enquanto umas germinam com menor volume de água, outras já necessitam de um volume maior. Segundo Cardoso (2004) aquelas sementes que necessitam de maiores quantidade de água para germinar, porém, sem excesso, podem ser classificadas sementes mesófilas.

A necessidade de menores níveis de água na fase inicial de germinação podem representar vantagens ecológicas às espécies. Conforme Guedes et al. (2010) espécies que necessitam de menor disponibilidade hídrica podem ser indicadas para compor áreas de clareiras, enquanto que aquelas que necessitam de maior quantidade são mais recomendadas para uso em áreas sombreadas.

Os dados de comprimento e massa seca da parte aérea de plântulas, não se ajustaram a nenhum modelo de regressão polinomial, sendo estes expressos pela média (Figura $2 \mathrm{~A}$ e C). Contudo, quando os dados foram submetidos ao teste de médias, observou-se diferença significativa apenas para o comprimento de parte aérea (Tabela 2), sendo os melhores valores obtidos na faixa de volume de água de 1,0 a 2,0 vezes o peso seco do substrato.

Esses resultados confirmam que a $A$. niopoides requer volumes menores de água nas fases iniciais do processo de germinação, o que pode estar relacionado ao tamanho da semente e as exigências da espécie. Desse modo, pode-se inferir que a espécie em estudo apresente vantagens ecológicas para garantir sua sobrevivência e estabelecimento em locais onde as que necessitam de maiores volumes de água, nas fases iniciais de germinação, não germinam. Resultados semelhantes ao observado nesse estudo foram obtidos por Abensur et al. (2007) em sementes de Jacaranda copaia (Aubl.) D. Don, que verificaram que para comprimento da parte aérea das plântulas não houve diferença entre os volumes de água testados $(1,5 ; 2,0 ; 2,5$ e 3,0 vezes o peso do substrato seco). 
Figura 2. Valores médios do comprimento (cm.plântula $\left.{ }^{-1}\right)$ da parte aérea $(\mathrm{CPA})(\mathrm{A})$, comprimento da raiz primária $(\mathrm{CR})$ (cm.plântula ${ }^{-1}$ ) (B), massa seca da parte aérea (MSPA) (mg.plântula ${ }^{-1}$ ) (C) e massa seca do sistema radicular (MSR) (mg.plântula ${ }^{-1}$ ) (D) de plântulas e Albizia niopoides Benth..*Fator de multiplicação para determinação da quantidade de água para umedecimento do substrato.

A.

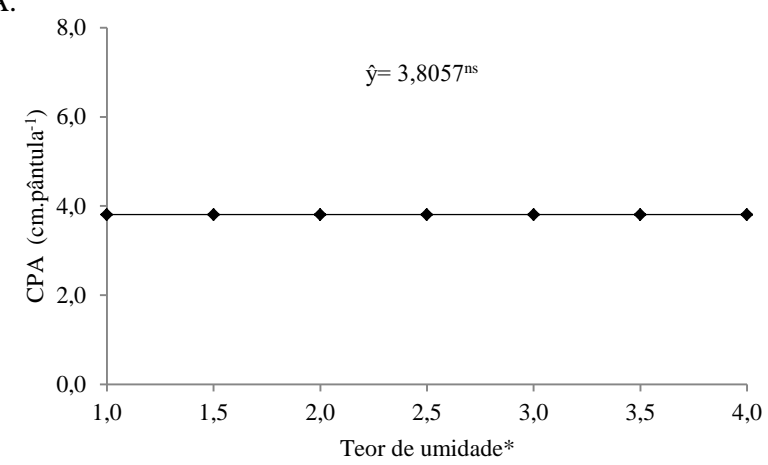

C.

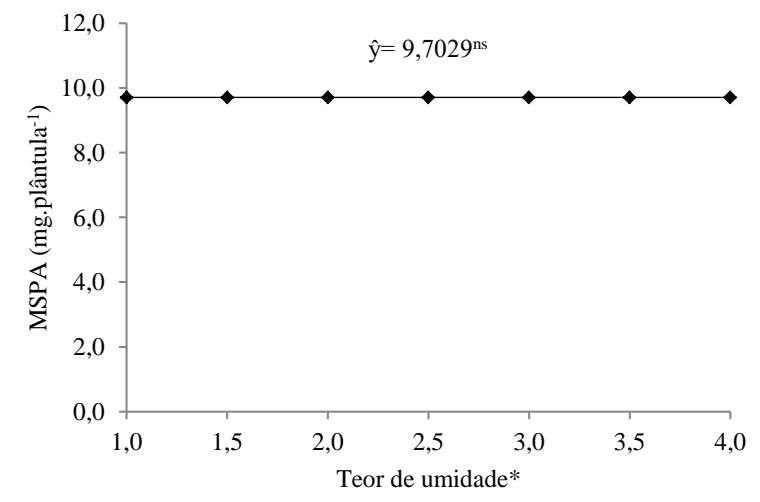

Os dados de comprimento da raiz primária e massa seca do sistema radicular de plântulas de $A$. niopoides ajustaram-se ao modelo de regressão cúbica, em função do aumento do volume de água no substrato (Figura $2 \mathrm{~B}$ e D). Os maiores valores foram observados quando se utilizou os volumes de água na faixa de 1,0 a 2,0 vezes o peso do papel seco (Tabela 2 ), sendo os maiores comprimentos de raiz $(4,72,4,28$ e 4,64 cm.plântula $\left.{ }^{-1}\right)$ e massa seca do sistema radicular $(3,17,2,82$ e 3,14 mg.plântula ${ }^{-1}$ ), respectivamente. Esse fato evidencia que o umedecimentoa partir de 2,5 vezes o peso seco do substrato, possivelmente afetou o processo de aeração, com consequências no desenvolvimento das plântulas. Varela et al. (2005) estudando sementes de Dinizia excelsa Ducke. sob diferentes volumes de água e temperaturas, encontraram resultados que corroboram os obtidos nesse estudo, para o comprimento de raiz primária, na temperatura de $25^{\circ} \mathrm{C}$.

Porém, vários outros estudos têm constatado bons resultados de germinação e vigor em amplitudes maiores de volumes de água $(2,0 ; 2,5 ; 3,0$ e 3,5 vezes o peso seco do substrato), a exemplo de Gonçalves et al. (2015) com Parkia platycephala Benth. e Guedes et al. (2010) com Amburana cearensis (Allemao) A.C. Smith. Já a espécie Peltogyne paniculata Benth., segundo Ramos et al. (2007), apresentou bons resultados na faixa de 1,5 a 3,0 vezes o peso do papel seco, com resultados variando de 2,1 a 4,3 cm.plântula ${ }^{-1}$, respectivamente. Para Mimosa caesalpiniifolia Benth. Nogueira et al. (2013) estudando a germinação de sementes sob diferentes substratos e temperaturas, obtiveram um valor médio de $6,3 \mathrm{~cm}$. plântula ${ }^{-1}$ para comprimento de raiz, quando
B.

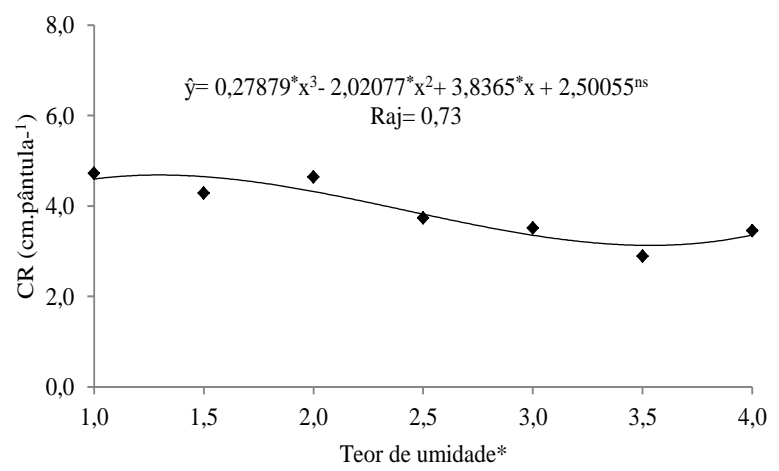

D.

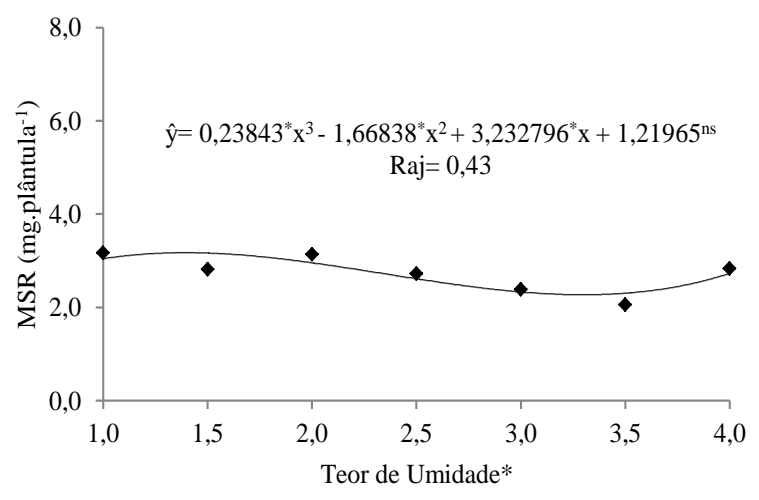

colocadas para germinar a $25^{\circ} \mathrm{C}$ em rolo de papel germitest, umedecido com 2,5 vezes o peso do papel seco.

Diante do que foi apresentado, evidencia-se que o teor de umidade que potencializa a germinação de sementes de uma determinada espécie pode não ser influenciado apenas por um único volume de água, mas sim por uma faixa de volumes específica, e, essa varia de acordo com a espécie, demostrando assim, a importância da realização de estudos abordando este tema.

\section{CONCLUSÕES}

Os volumes de água na faixa de 1,0 a 2,0 vezes o peso do papel seco, favorecem a germinação e o vigor das sementes de A. niopoides.

\section{REFERÊNCIAS}

ABENSUR, F. O.; MELO, M. de F. F.; RAMOS, M. B. P.; VARELA, V. P.; BATALHA, L. P. Tecnologia de sementes e morfologia da germinação de Jacaranda copaia D. Don (Bignoniaceae). Revista Brasileira de Biociências, Porto Alegre, v.5, n.2, p.60-62, 2007.

ALBUQUERQUE, A. N. de; ALBUQUERQUE, M. C. de F. e; MARIANO, D. de C.; OKUMURA, R. S.; NASCIMENTO, D. S. Umedecimento do substrato na emergência e desenvolvimento de plântulas de sucupira-preta. Enciclopédia biosfera, Goiânia, v.9, n.16, p.2050, 2013. 
AZEREDO, G. A. de; SILVA, B. M. da S. e; SADER, R.; MATOS, V. P. Umedecimento e substratos para germinação de sementes de repolho. Pesquisa Agropecuária Tropical, Goiânia, v.40, n.1, p.77-82, 2010.

BARROS, S. S. U.; SILVA, A. da.; AGUIAR, I. B. Germinação de sementes de Gallesia integrifolia (Spreng.) Harms (pau-dalhoff) sob diferentes condições de temperatura, luz e umidade do substrato. Revista Brasileira de Botânica, São Paulo, v.28, n.4, p.727-733, 2005.

BARROSO, L. M.; ALVES, E. U.; SILVA, R. dos S.; ANJOS NETO, A. P. dos; SANTOS NETA, M. das M. S. dos; SILVA, B. F. da. Substratos e temperaturas para testes de germinação e vigor de sementes de Inga laurina (sw.) Willd. Bioscience Journal, Uberlândia, v.30, n.1, p.252-261, 2014.

BEWLEY, J. D.; BRADFORD, K. J.; HILHORST, H. W. M.; NONOGAKI, H. Seeds: physiology of development, germination and dormancy. Nova York: Springer, 2013. 392 p.

BRASIL. Ministério da Agricultura, Pecuária e Abastecimento. Secretaria de Defesa Agropecuária. Regras para análise de sementes. 1 ed. Brasília: Mapa/ ACS. 2009. $365 \mathrm{p}$.

CARDOSO, V. J. M. Germinação de Sementes. In: KERBAUY, G.B. (Org). Fisiologia Vegetal. Rio de Janeiro: Editora Guanabara Koogan, 2004. p.386-408.

CARVALHO, N. M.; NAKAGAWA, J. Sementes: ciência, tecnologia e produção. 5.ed. Jaboticabal: FUNEP, 2012. 590p.

CARVALHO, P. E. R. Farinha-seca - Albizia niopoides. Comunicado técnico 226. Embrapa Florestas, p.1-8, 2009.

FIGLIOLIA, M. B. Teste de germinação. In: PIÑARODRIGUES, F. C. M.; FIGLIOLOA, M. B.; SILVA, A. (eds.). Sementes Tropicais Florestais: da ecologia à produção, Londrina, Pr: ABRATES, 2015. Cap.5, p.325-343.

FLORES, A. V.; ATAÍDE, G. da M.; BORGES, E. E. de L.; GONÇALVES, L. E. S.; MANFIO, C. E. Umedecimento do substrato e temperatura na germinação de sementes de Melanoxylon brauna Schott. Revista Brasileira de Ciências Agrárias (Agrária), Recife, v.8, n.3, p.454-457, 2013.

GONÇALVES, E. P.; FRANÇA, P, R, C. de; VIANA, J, S.; AlVES, E, U.; GUEDES, R, S.; LIMA, C, R. de. Umedecimento do substrato e temperatura na germinação de sementes de Parkia platycephala BENTH. Ciência Florestal, Santa Maria, v.25, n.3, p.563-569, 2015.

GUEDES, R. S.; ALVES, E. U.; GONÇALVES, E. P.; VIANA, J. S.; FRANÇA, P. R. C. de; LIMA, C. R. de. Umedecimento do substrato e temperatura na germinação e vigor de sementes de Amburana cearensis (All.) A.C. Smith. Revista Brasileira de Sementes, Londrina, v.32, n.3, p.116122, 2010.
KRZYZANOWSKI, F. C.; VIEIRA, R. D.; FRANÇA NETO, J. de B. Vigor de sementes: conceitos e testes. Londrina: ABRATES, 1999. 218p.

LORENZI, H. Árvores brasileiras: manual de identificação e cultivo de plantas arbóreas nativas do Brasil. 2 ed. Nova Odessa: Plantarum, 2002. 368 p.

MARCOS-FILHO, J. Fisiologia de sementes de plantas cultivadas. 2 ed. Londrina: Associação Brasileira de Tecnologia de Sementes - ABRATES, 2015. 659p.

MARTINS, C. C.; BOVI, M. L. A.; SPIERING, S. H. Umedecimento do substrato na emergência e vigor de plântulas de pupunheira. Revista Brasileira de Fruticultura, Jaboticabal, v.31, n.1, p.224-230, 2009.

MARTINS, C. C.; MACHADO, C. G.; CALDAS, I. G. R.; VIEIRA, I. G. Vermiculita como substrato para o teste de germinação de sementes de Barbatimão. Ciência Florestal, Santa Maria, v.21, n.3, p.421-427, 2011.

MARTINS, C. C.; MACHADO, C. G.; SANTANA, D. G.; ZUCARELI, C. Vermiculita como substrato para o teste de germinação de sementes de ipê-amarelo. Semina: Ciências Agrárias , v. 33, n. 2, p. 533-540, 2012.

MELO, R. R. de; FERREIRA, A. G.; JÚNIOR, F. R.. Efeito de diferentes substratos na germinação de sementes de angico (Anadenanthera colubrina (Vell.) Brenan) em condições de laboratório. Revista Científica Eletrônica de Engenharia Florestal, Garça, v.5, p.1678-3867, 2005.

NAKAGAWA, J. Teste de vigor baseados no desempenho das plântulas. In: KRZYZANOWSKI, F. C.; VIEIRA, R. D.; FRANÇA NETO, J. de B. (eds). Vigor de sementes: conceitos e testes. Londrina: ABRATES, 1999, p. 2.1- 2.21.

NOGUEIRA, N. W.; RIBEIRO, M. C. C.; FREITAS, R. M. O. de; GURGEL, G. B.; NASCIMENTO I. L. do. Diferentes temperaturas e substratos para germinação de sementes de Mimosa caesalpiniifolia Benth. Revista de Ciências Agrárias, Belém, v.56, n.2, p.95-98, 2013.

NOVEMBRE, A. D. L. C.; MARCOS FILHO, J. Estudo da metodologia para condução do teste de germinação em sementes de algodão deslintadas mecanicamente. Revista Brasileira de Sementes, Curitiba, v.21, n.2, p.187-193, 1999.

QUEIROZ DINIZ, R. de; DINIZ, B. L. M. T.; AZEREDO, G. A. de; SOUZA, V. C. de; PEREIRA, E. M. Potencial germinativo de sementes de Aroeira Myracrodruon urundeuva Fr. coletadas de população no cariri paraibano. Revista Verde de Agroecologia e Desenvolvimento Sustentável, v.10, n.1, p.154-159, 2015.

RAMOS, M. B. P.; VARELA, V. P.; MELO, M. de. F. F. Influência da temperatura e da água sobre a germinação de sementes de paricá (Schizolobium amazonicum Huber ex Ducke-Leguminosae-Caesalpinioideae). Revista Brasileira de Sementes, Londrina, v.28, n.1, p.163-168, 2006 a. 
RAMOS, M. B. P.; VARELA, V. P.; MELO, M. de F. F. Influência da temperatura e da quantidade de água no substrato sobre a germinação de sementes de Ochroma pyramidale (Cav. ex Lam.) Urban (pau-de-balsa). Acta Amazonica, Manaus, v.36, n.1, p.103-106, 2006 b.

RAMOS, M. B. P.; VARELA, V. P.; RIBEIRO, M. N.; MAFRA, R. M.; BATALHA, L. F. P. Volume de água no substrato e temperatura na germinação de sementes de Mulateiro (Peltogyne paniculata Benth.). Revista de Ciências Agrárias, Belém, n. 48, p.193-203, 2007.

REGO, S. S.; NOGUEIRA, A. C.; KUNIYOSHI, Y. S.; SANTOS, A. F. dos. Germination of seeds of Blepharocalyx salicifolius (HBK) Berg. in different substrates and conditions of temperatures, light and moisture. Revista Brasileira de Sementes, Londrina, v.31, n.2, p.212-220, 2009.

SILVA, M. D; NAKAGAWA, J.; FIGLIOLIA, M. B. Influência da temperatura, da luz e do teor de água na germinação de sementes de Schinus terebinthifolius RaddiAnacardiaceae (aroeira-vermelha). Revista do Instituto Florestal, São Paulo, v.13, n.2, p.135-146, 2001.

SILVA, H. P. da; NEVES, J. M. G.; BRANDÃO JUNIOR, D. da S.; COSTA, C. A. da. Quantidade de água do substrato na germinação e vigor de sementes de pinhão-manso. Revista Caatinga, Mossoró, v. 21, n.5, p.178-184, 2008.

STATSOFT INC. Statistica data analysis system version 8.0. Tulsa: 2008.

TANAKA, M. A. de S.; MARIANO, M. I. A.; LEÃO, N. V. M. Influência da quantidade de água no substrato sobre a germinação de sementes de amendoim. Revista Brasileira de Sementes, Brasília, v.13, n.1, p.73-76, 1991.

VARELA, V. P.; RAMOS, M. B. P.; MELO, M. de F. F. Umedecimento do substrato e temperatura na germinação de sementes de angelim-pedra (Dinizia excelsa Ducke). Revista Brasileira de Sementes, Londrina, v.27, n.2, p.130-135, 2005. 